\title{
Rekürren biliyer pankreatit nasıl önlenebilir? Olgu sunumu ve literatür derlemesi
}

\section{How the recurrence of biliary pancreatitis can be prevented? A case report and literature review}

\author{
Fatih Başak ${ }^{1}$, Ali Tardu ${ }^{2}$, Mert Mahsuni Sevinç ${ }^{2}$, Erdem Kınacı ${ }^{2}$, Acar Aren ${ }^{2}$
}

Öz

Rekürren akut pankreatit, klinik uygulamada hala kompleks bir tanı ve tedavi olarak karşımıza çıkmaktadır. Pankreatitte tekrarlayan ataklar çoğunlukla teşhis sırasında normal bir morfoloji gösteren bir bezde görülür, bu yüzden böylesi bir klinik varlığın norma pankreasta tekrarlanan pankreatit ataklarıyla karakterize olduğuna inanılır. Rekürren akut pankreatitli hastaların değerlendirilmesi, düzeltilebilir faktörlerinin sistematik tanımlanmas veya ortadan kaldırılmasını gerektirir. Bu çalışmada, altı kez atak ile başvuran aku pankreatit olgusunu literatür eşliğinde sunmayı amaçladık.

Anahtar Kelimeler: Pankreatit, Rekürrens, Kolesistektomi, Endoskopik sfinkterotomi

\section{Abstract}

Diagnosis and treatment of recurrent acute pancreatitis remains a complex issue in clinical practice. Repeated episodes of pancreatitis are usually seen in a gland with a normal morphology during diagnosis, so it is believed that such a clinical entity is characterized by recurrent episodes of pancreatitis in the normal pancreas. The evaluation of patients with recurrent acute pancreatitis requires systematic identification or removal of correctable factors. In this study, we aimed to present a case of acute pancreatitis with six attacks in the light of the literature.

Keywords: Pancreatitis, Recurrence, Cholecystectomy, Endoscopic sphincterotomy

\section{Giriş}

Akut pankreatit (AP), pankreas bezinin akut bir inflamasyonudur ve çeşitl etyolojilerin sebep olduğu bir durum olup, safra taşları atakların \%50-70'inden sorumludur. Başlangıçta akut pankreatit ataklarına neden olabilecek herhangi bir faktör, tekrarlayan ataklar başlatma potansiyeline sahiptir [1]. AP'den dolayı başvuruların \%27'sini tekrarlayan ataklar oluşturur ve kolelitiazis bunların dörtte birinden sorumludur [2]. Bu çalışmada altı kez tekrarlayan ataklarla tanı ve tedavisi gerçekleştirilen bir AP olgusunu literatür eşliğinde sunmayı amaçladık.

\section{Olgu sunumu}

Altmış dokuz yaşında kadın hasta karın ağrısı, bulantı ve kusma şikayetleriyle başvurdu. Özgeçmişinde diabet, hipertansiyon ve kalp yetmezliği mevcuttu. Fizik muayenede sağ üst kadran ve epigastrik bölgede hassasiyet mevcuttu, akut karın bulguları saptanmadi. Laboratuar değerlendirmeleri lökosit: $16.000 / \mathrm{mm}^{3}$, glukoz: $165 \mathrm{mg} / \mathrm{dl}$, LDH: $300 \mathrm{IU} / \mathrm{L}$, AST: $200 \mathrm{IU} / \mathrm{L}$, Amilaz > $1300 \mathrm{IU} / \mathrm{ml}$ olup ilk başvuruda Ranson skoru 2 olarak hesaplandı. Ultrasonografide safra kesesi içinde multipl kalküller ve akut kolesistit ile uyumlu bulgular saptandı. Bilgisayarlı tomografide (BT) akut pankreatit ile uyumlu bulgular görüldü. Endoskopik retrograd kolangio pankreatografi (ERCP) işlemi ile sfinkterotomi yapıldı. Koledok içerisinde milimetrik safra taşları olduğu ve sfinkterotomi sonrası bunların duodenuma boşaldığı görüldü. Şikayetlerinin düzelmesi ile taburcu edildi (yatış süresi 7 gün). On gün sonra benzer şikayetler ile başvurdu. Hasta akut pankreatit olarak değerlendirilip, tekrar hastaneye yatışı yapıldı. Bilgisayarlı tomografide (BT) peripankreatik bölgede \%50'yi aşan sıvı kolleksiyonları ve içerisinde heterojen solid bileşenler olduğu görüldü (Resim 1a). Şikayetlerinin düzelmesi ile taburcu edildi (yatış süresi 8 gün). Elli altı gün sonra benzer şikayetler ile başvurdu. Ranson skoru 2 olan akut pankreatit olarak değerlendirildi. BT'de sıvı kolleksiyonlarında ve içerisindeki heterojen solid bileșenlerde gerileme görüldü (Resim 1b).

\author{
${ }^{1}$ Ümraniye Eğitim ve Araştırma Hastanesi, \\ Genel Cerrahi Kliniği, İstanbul, Türkiye. \\ ${ }^{2}$ İstanbul Eğitim ve Araştırma Hastanesi, \\ Genel Cerrahi Kliniği, İstanbul, Türkiye. \\ Conflict of Interest: No conflict of interest was declared \\ by the authors. \\ Çıkar Çatışması: Yazarlar çıkar çatışması \\ bildirmemişlerdir. \\ Financial Disclosure: The authors declared that this case \\ has received no financial support. \\ Finansal Destek: Yazarlar bu olgu için finansal destek \\ almadıklarını beyan etmişlerdir. \\ Geliş Tarihi / Received \\ 24.12.2016 \\ Kabul Tarihi / Accepted \\ 28.12.2016 \\ Yayın Tarihi / Published \\ 30.12.2016 \\ Sorumlu yazar / Corresponding author \\ Fatih Basak \\ Adres: Ümraniye Eğitim ve Araştırma Hastanesi, Genel \\ Cerrahi Kliniği, Adem Yavuz sok, No: 2, Ümraniye, \\ 34766, İstanbul, Türkiye \\ Tel: +90216 6321818 \\ e-posta: fatihbasak@gmail.com \\ CC Copyright 2017 ACEM
}

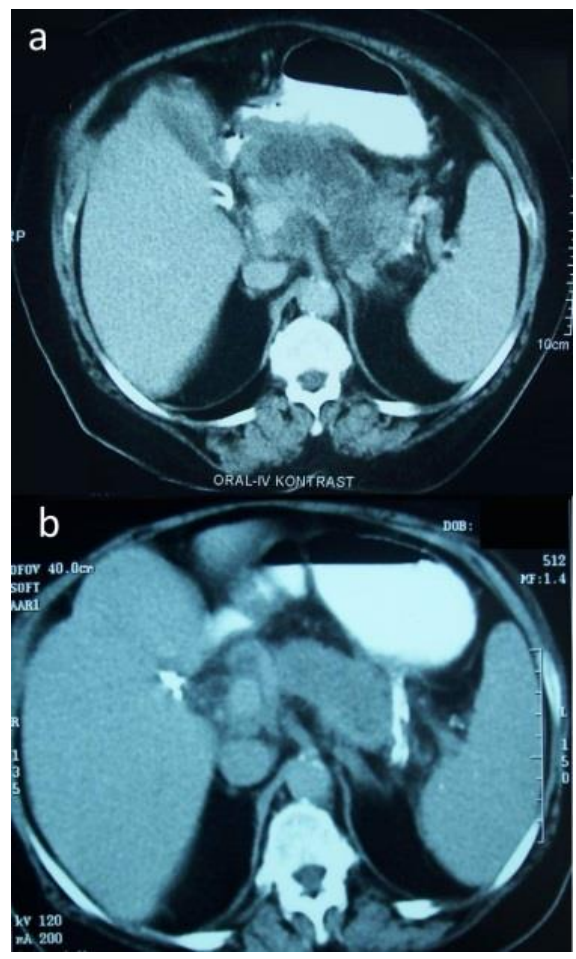

Resim 1: Bilgisayarlı tomografi görüntüsü (a: 2.yatış, b: 4.yatış) 
Aynı yatışta laparoskopik kolesistektomi yapıldı. Düzelme sonrası taburcu edildi (yatış süresi 13 gün). On bir gün sonra tekrar başvurdu. Yeni bir AP atağı olarak değerlendirildi ve 4. yatış yapıldı. Destek tedavisi sonrası taburcu edildi (yatış süresi 13 gün). Bir gün sonra tekrar başvurdu ve 5. yatış yapıldı. Destek tedavisi sonrası taburcu edildi (yatış süresi 10 gün). Sekiz gün sonra tekrar başvurdu. Benzer laboratuvar ve klinik bulgularla 6 . yatış yapıldı. Destek tedavisi sonrası taburcu edildi (yatış süresi 11 gün). Altı aylık takibinde herhangi bir sorun görülmedi. Hastanın yatış süreçleri tablo 1 'de özetlenmiştir.

Tablo 1: Hastanın yatış süreçleri

\begin{tabular}{|l|c|c|l|}
\hline Yatı̧̧lar & $\begin{array}{l}\text { Ataksız- } \\
\text { Yatışsız } \\
\text { süre }\end{array}$ & $\begin{array}{l}\text { Yatış } \\
\text { süresi } \\
\text { (gün) }\end{array}$ & Tetkik- İşlem \\
\hline 1 & 10 & 8 & USG, BT, ERCP \\
\hline 2 & 56 & 13 & BT, Lap. Kol. \\
\hline 3 & 11 & 13 & BT \\
\hline 4 & 1 & 10 & \\
\hline 5 & 8 & 11 & BT \\
\hline 6 & $\begin{array}{l}62 \text { gün } \\
(/ 142 \\
\text { gün) }\end{array}$ & \begin{tabular}{l} 
USG, 5 BT, ERCP, Kol. \\
\hline Toplam
\end{tabular} \\
\hline
\end{tabular}

USG: Ultrasonografi, BT: Bilgisayarlı tomografi, ERCP: Endoskopik retrograd kolangio pankreatografi, Lap. Kol.: Laparoskopik kolesistektomi

\section{Tartışma}

AP'nin patogenezinde genellikle iki mekanizma olduğu kabul edilir: safra yolunda safra reflüsü ve en önemlisi, göç edici taş veya ampulladaki impakte bir taştan kaynaklanan geçici ampulla tıkanıklığı [3]. AP olgularında safra kesesi bırakıldığında \%75-90'a kadar nüksler bildirilmiştir, ve kolesistektominin bu hastalarda tekrarlama riskini \%10 oranına azalttığı bilinmektedir [4]. Bu nedenle, AP hastalarında, hastanın ameliyat olmak için uygun olması durumunda kolesistektomi yapılması ve ortak safra kanalı taşlarının ERCP ile çıkarılması önerilmektedir [5, 6]. Yüksek cerrahi riski olan veya kolesistektomi istemeyen hastalarda, endoskopik sfinkterotomi (ES) kolesistektomiye alternatif olabilir [7, 8].

Cerrahiye uygun hastalarda kolesistektomi ve ortak safra kanalı taşlarının çıkarılması, hastalığın tekrarını önlemek için önerilmektedir. Cerrahinin zamanlaması tartışmalıdır. Bazı yazarlar acil ameliyatı (ilk 48 saat içinde) savunurken, diğerleri erken cerrahiyi desteklemektedir (ilk başvuruda tıbbi destek tedavisinden sonra) $[9,10]$. Yine de, gecikmiş cerrahi (AP atağının iyileşmesinden sonra ikinci bir AP başvurusunda) değerlendirildiğinde, yüksek nüks oranı saptanmıştır (\% 49-61) [11]. AP'nin klinik kılavuzlarında gösterildiği gibi şu anda, cerrahinin zamanlaması konusunda büyük bir uzlaşma vardır $[7,8]$. Hafif AP'de kolesistektomi, ilk başvuru sırasında veya en azından ilk 4 hafta içinde yapılmalıdır. Kolesistektomi için zamanlama şiddetli formlarda o kadar net değildir. Tekrar atak gelişiminin önlenmesinde ERCP'nin rolü üzerine yapılan çalışmalar, ES'nin yüksek cerrahi riski olan veya kolesistektomi geçirmek istemeyen hastalarda kolesistektomiye bir alternatif olabileceğini göstermektedir [8]. Bizim olgumuzda ilk başvuruda ES yapıldı, ancak yineleme olunca kolesistektomi yapıldı. $\mathrm{Bu}$ varsayımları kanitlamak zor olmakla birlikte: ilk iki atak birbirini devamı olabilir, ya da ikinci atak ERCP işlemine sekonder gelişmiş olabilir.

Villoria ve ark. [12], nükslerin \%50'sinin ilk iki ay içinde meydana geldiğini bildirdi. Frei ve ark. [13] rekürrenslerin \%52.1'ini, AP atağından sonraki ilk 6 hafta içinde gözledi. İlgili çalışmada, tekrarlayan atakların \%90'ı safra kesesi mevcut olan hastalarda görüldü. Nükslerin \%4'ü koledokolitiazise bağlıydı ve atakların \%6'sı idiyopatik olarak kabul edildi. İlk atak şiddetli olursa, tekrarlayan atakların daha sık ağır olduğuna dikkat çekilmektedir [14]. Bizim olgumuzda ikinci atak şiddetli AP olarak tespit edildi. Ilk iki atak sırasında ES ve kolesistektomi işlemleri uyguland 1 ancak dört kez daha AP yinelemesi tespit edildi. İkinci yinelemeden sonra gelişen yinelemeler için, "atak değil psödokist oluşumu" gibi hipotezler düşünülebilir. Ancak diğer ataklarda tetkikler esnasında görüntülemelerde psödokist saptanmamıştır. Bu tekrarlayan atak durumlarının, ikinci atakta gelişen şiddetli pankreatit tablosunun şiddetine bağlı olduğunu düşünmekteyiz. $\mathrm{Bu}$ durum, etkin bir şekilde tedavi edilememiş şiddetli bir akut pankreatit tablosunun da akılda tutulmasını gerekli kılmaktadır.

Sonuç olarak, kolesistektomi uygulanmazsa, AP rekürrensi sık görülen bir olaydır. Ancak kolesistektominin gecikmesi, nüks için bir risk faktörü olarak belirlenememiştir. $\mathrm{Bu}$ nedenle, mevcut klinik uygulamada k1lavuzlara uymak için çaba gösterilmelidir. Cerrahiye uygun olmayan veya kolesistektomi yapılmasını reddeden hastalarda nüksün önlenmesi için ES kabul edilebilir bir tedavi seçeneği olabilir. Cerrahi riski olmayan (cerrahiyi uygun, ancak ameliyatı kabul etmeyen hasta) hastalarda rekürrensi önlemek için ES'nin rolünü belirlemek için daha ileri çalışmalara ihtiyaç vardır.

\section{Kaynakça}

1. Somogyi L, Martin SP, Venkatesan T, Ulrich CD 2nd. Recurrent acute pancreatitis: An algorithmic approach to identification and elimination of inciting factors. Gastroenterology 2001;120:708-17.

2. Gullo L, Migliori M, Pezzilli R, Oláh A, Farkas G, Levy P, Arvanitakis C, Lankisch P, Beger H. An update on recurrent acute pancreatitis: Data from five European countries. Am J Gastroenterol 2002;97:1959-62.

3. Acosta JM, Ledsesma CL. Gallstone migration as a cause of acute pancreatitis. N Engl J Med 1974;290:484-7.

4. Kelly TR, Swaney PE. Gallstone pancreatitis. The second time around. Surgery 1987;92:571-5.

5. Dervenis C, Johnson CD, Bassi C, Bradley E, Imrie CW, McMahon MJ, Modlin I. Diagnosis, objective assessment of severity, and management of acute pancreatitis. Santorini consensus conference. Int $\mathrm{J}$ Pancreatol 1999;25:195-210.

6. United Kingdom guidelines for the management of acute pancreatitis. Gut 1998;42(Suppl 2):S1-13.

7. Billi P, Barakat B, D'Imperio N, Pezzilli R. Relapses of biliary acute pancreatitis in patients with previous attack of biliary pancreatitis and gallbladder in situ. Dig Liver Dis 2003;35:653-5.

8. Kaw M, Al-Antably Y, Kaw P. Management of gallstone pancreatitis: Cholecystectomy or ERCP and endoscopic sphincterotomy. Gastrointest Endosc 2002;56:61-5.

9. Stone HH, Fabian TC, Dunlop WE. Gallstone pancreatitis. Biliary tract pathology in relation to time of operation. Ann Surg 1981;194:305-312.

10. Kelly TR, Wagner DS. Gallstone pancreatitis: A prospective randomized trial of the timing of surgery. Surgery1988;104:600-5.

11. Alimoglu O, OzkanOV, Sahim M, et al. Timing of cholecystectomy for acute biliary pancreatitis: Outcomes of cholecystectomy on first admission and after recurrent biliary pancreatitis. World J Surg 2003;27:256-9.

12. Villoria A, Maristany C, Olsina J, et al. Recidiva de pancreatitis biliar (abstract). Gastroenterol Hepatol 2002;25:366

13. Frei GJ, Frei VT, Thirlby RC, McClelland RN. Biliary pancreatitis: Clinical presentation and surgical management. Am J Surg 1986;151:170-5.

14. Hernandez V, Pascual I, Almela P, Añon R, Herreros B, Sanchiz V, Minguez M, Benages A. Recurrence of acute gallstone pancreatitis and relationship with cholecystectomy or endoscopic sphincterotomy. Am J Gastroenterol. 2004;99:2417-23. 